\title{
Study on fetomaternal outcome in short interpregnancy interval: case control study
}

\author{
Preeti Lewis, Shreya Mor*
}

Department of Obstetrics and Gynecology, Grant Government Medical College and JJ Group of Hospital, Mumbai, Maharashtra, India

Received: 07 November 2019

Revised: 04 December 2019

Accepted: 13 December 2019

\section{*Correspondence:}

Dr. Shreya Mor,

E-mail: shreyamor74@gmail.com

Copyright: () the author(s), publisher and licensee Medip Academy. This is an open-access article distributed under the terms of the Creative Commons Attribution Non-Commercial License, which permits unrestricted non-commercial use, distribution, and reproduction in any medium, provided the original work is properly cited.

\begin{abstract}
Background: This study was carried out at a tertiary health centre with the aim of studying the effect of short interpregnancy interval on fetomaternal outcome. The maternal complications and fetal complications of short interpregnancy interval were analysed in comparison to normal interpregnancy interval.

Methods: This is a case control study. 125 women with short interpregnancy interval seeking healthcare at tertiary health care centre were matched with 125 women with normal interpregnancy interval on the basis of demographic characteristics like age, height, weight and socio-economic status. These were included in the case control study.

Results: Short interpregnancy interval is associated with increased risk of anemia, premature rupture of membranes (PROM), scar dehiscence and low birth weight whereas normal interpregnancy interval is associated with increased risk of PIH as compared to short interpregnancy interval.

Conclusions: Short interpregnancy interval is associated with increased risk of anemia, PROM, scar dehiscence and low birth weight whereas normal interpregnancy interval is associated with increased risk of PIH.
\end{abstract}

Keywords: Anemia, Chi square test, Pregnancy-induced hypertension, Premature rupture of membranes, Normal interpregnancy interval, Short interpregnancy interval

\section{INTRODUCTION}

Pregnancy spacing refers to the practice of maintaining an interval between births of two or more years.

Interpregnancy Interval- It is defined as the period between delivery of previous infant and conception of current pregnancy. ${ }^{1}$

Based on six USAID-sponsored studies, WHO has recommended the following to reduce the risk of adverse maternal and perinatal outcomes:
- After a live birth, the recommended minimum interval before attempting the next pregnancy is at least 24 months.

- After a miscarriage or induced abortion, the recommended interval to next pregnancy is atleast six months. ${ }^{2}$

The adverse consequences of a short birth interval for infant and child survival have centered on three causal mechanisms:

- Biological effects related to "maternal depletion syndrome" or more generally the woman not 
recuperating from one pregnancy before supporting the next.

- Behavioral effects associated with competition between siblings or the inability to give a child adequate attention

- Disease transmission. ${ }^{3}$

Short interpregnancy interval is associated with multiple health and nutrition effects on both, mother and child. Short intervals between pregnancies is associated with an increased risk for adverse pregnancy outcomes like preterm delivery, low birth weight, small for gestational age, low Apgar score, maternal anemia, dystocia, rupture of uterus, maternal morbidity and mortality. Women with short interpregnancy interval are also at an increased risk for failure of trial of VBAC, $\mathrm{PPH}$ and pre-eclampsia.

\section{METHODS}

This study was carried out at our tertiary care centre. 125 women with short interpregnancy interval and 125 women with normal interpregnancy interval were matched on the basis of demographic characteristics like age, height, weight and socio-economic status and selected and the pregnancy outcome along with maternal and fetal complications were studied.

\section{Inclusion criteria}

- All pregnant women with previous pregnancy, irrespective of outcome of pregnancy who attend the ANC clinic-booked, unbooked and referred at our Institute.

\section{Exclusion criteria}

- Primigravidas.

This is case control study. From December 2018 to March 2019. All pregnant women with previous pregnancy, irrespective of outcome of pregnancy who attend the ANC clinic-booked, unbooked and referred at our Institute. The women were divided into two groups based on their interpregnancy interval (short and normal) and were matched on the basis of demographic characteristics.

This is a case control study carried out at our tertiary care centre. Women were divided into two groups based on their interpregnancy interval (short and normal) and were matched on the basis of demographic characteristics. Pregnancy outcome- maternal and fetal were studied in both groups- women with short and normal interpregnancy interval. The incidence of complications was studied in both groups.

\section{Statistical analysis}

For anemia, the Chi square statistic (df-1 and level of significance 0.05 ) was 4.8 and P-value was 0.028 , which is statistically significant. For scar dehiscence, the Chi square statistic (df-1 and level of significance 0.05 ) was 16.97 and P-value was 0.000038 , which is statistically significant. For PROM, the Chi square statistic (df-1 and level of significance 0.05 ) was 5.45 and P-value was 0.019 , which is statistically significant. For LBW, the Chi square statistic (df-1 and level of significance 0.05 ) was 4.28 and P-value was 0.38 , which is statistically significant. For PIH, the Chi square statistic (df-1 and level of significance 0.05) was 9.17 and P-value was 0.024 , which is statistically significant. However, for preterm labour, the Chi square statistic (df-1 and level of significance 0.05 ) was 3.4 and $\mathrm{P}$ value was 0.65 , which is not statistically significant.

\section{RESULTS}

In this study it was seen that, out of the cases studied, maximum were registered patients with a normal interpregnancy interval (68.8\%), as shown in Table 1.

Table 1: Distribution of cases as per registered/referred.

\begin{tabular}{|lllll|}
\hline & No. of cases & Percentage & No. of cases & Percentage \\
\hline & Short ICP & & Normal ICP & 68.8 \\
\hline Registered & 79 & 63.2 & 86 & 31.2 \\
\hline Referred & 46 & 36.8 & 39 & \\
\hline
\end{tabular}

As shown in Figure 1, anemia was the most common complication, in both women with short $(66 \%)$ and normal $(52.8 \%)$ interpregnancy interval. Scar dehiscence, PROM and preterm labour were seen commonly in women with short interpregnancy interval whereas PIH was the second most common complication in women with normal interpregnancy interval.

Chi square test was applied, at P-0.05, short ICP is associated with increased incidence of anemia, scar dehiscence and PROM whereas normal ICP is associated with increased incidence of PIH. For anemia, the Chi square statistic (df-1 and level of significance 0.05 ) was 4.8 and P-value was 0.028 , which is statistically significant. For scar dehiscence, the Chi square statistic (df-1 and level of significance 0.05) was 16.97 and $\mathrm{P}$ value was 0.000038 , which is statistically significant. For PROM, the Chi square statistic (df-1 and level of significance 0.05 ) was 5.45 and P-value was 0.019 , which is statistically significant. The prevalence of other 
maternal complications was studied among women with short and normal interpregnancy interval, but the difference was not found to be statistically significant.

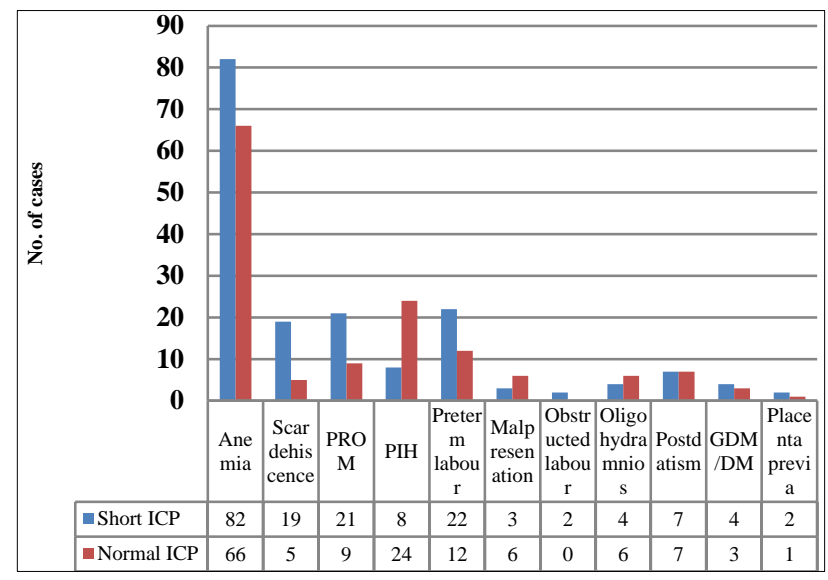

Figure 1: Distribution of cases as per significant maternal complication (antenatal).

As shown in Table 2, lower segment cesarean section was seen more commonly in women with short interpregnancy interval. Vaginal birth after cesarean section was seen more commonly in women with normal interpregnancy interval (11.7\%).

As shown in Table 3, scar dehiscence was the most common indication for lower segment cesarean section among women with both short (36\%) and normal (26\%) interpregnancy interval. Previous 2 LSCS (21\%) and malpresentation $(10.5 \%)$ were the other common indications for lower segment cesarean section among women with normal interpregnancy interval. Premature rupture of membranes (8.8\%), cephalopelvic disproportion and fetal distress $(7.3 \%)$ were the other common indications for lower segment cesarean section among women with normal interpregnancy interval.

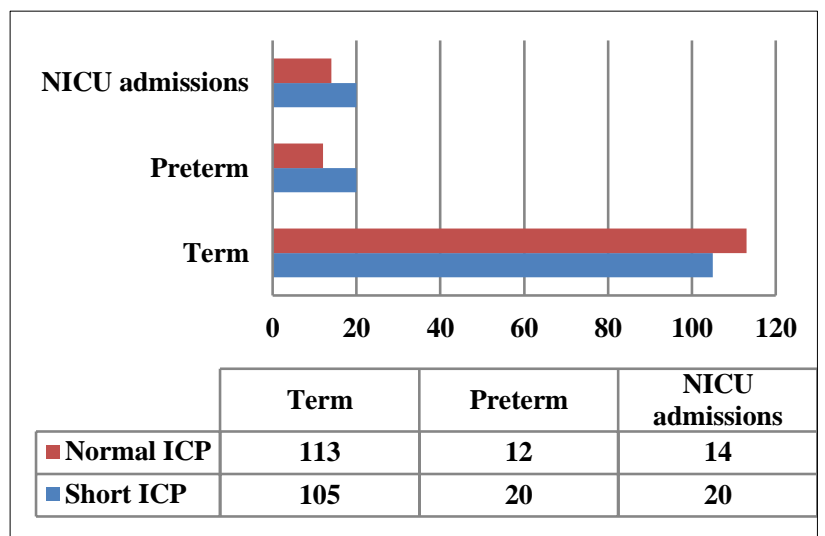

Figure 2: Distribution of cases as per fetal outcomes.

As shown in Figure 2, NICU admission and preterm infants were seen more commonly in women with short interpregnancy interval than those of normal interpregnancy interval.

Table 2: Distribution of cases as per mode of delivery.

\begin{tabular}{|lllll|}
\hline Mode of delivery & Short ICP & Percentage & Normal ICP & Percentage \\
\hline LSCS & 68 & 54.4 & 57 & 45.6 \\
\hline Vaginal & $57(1 \mathrm{VBAC})$ & 45.6 & $68(8 \mathrm{VBAC})$ & 54.4 \\
\hline
\end{tabular}

Table 2: Distribution of cases as per indication of LSCS.

\begin{tabular}{|lllll|}
\hline Indication of LSCS & No. of cases & Percentage & No. of cases & Percentage \\
\hline & Short ICP & & Normal ICP & \\
\hline Scar tenderness/ dehiscence & 25 & 36.7 & 15 & 26.3 \\
\hline Fetal distress & 5 & 7.3 & 3 & 5.2 \\
\hline Previous 2 LSCS & 4 & 5.8 & 12 & 21 \\
\hline Malpresentation & 3 & 4.4 & 6 & 10.5 \\
\hline CPD & 5 & 7.3 & 3 & 5.2 \\
\hline PROM & 6 & 8.8 & 4 & 7 \\
\hline BOH & 2 & 2.9 & - & - \\
\hline Obstructed labour & 2 & 2.9 & - & 3.5 \\
\hline Twins & 1 & 1.47 & 2 & 7 \\
\hline Not willing for VBAC & 5 & 7.3 & 4 & - \\
\hline FOI & 1 & 1.47 & - & 7 \\
\hline NPOL & 3 & 4.4 & 4 & 7 (1-placenta percreta) \\
\hline APH & - & - & 4 & \\
\hline
\end{tabular}

As shown in Table 4, LBW and preterm were seen more commonly among women with short interpregnancy interval. For LBW, the Chi square statistic (df-1 and level of significance 0.05 ) was 4.28 and P-value was 0.38 , 
which is statistically significant. For PIH, the Chi square statistic (df-1 and level of significance 0.05) was 9.17 and $\mathrm{P}$-value was 0.024 , which is statistically significant.
However, for preterm labour, the Chi square statistic (df1 and level of significance 0.05 ) was 3.4 and P-value was 0.65 , which is not statistically significant.

Table 4: Distribution of cases as per fetal complication.

\begin{tabular}{|lllll|}
\hline Complication & No. of cases & Percentage & No. of cases & Percentage \\
\hline & Short ICP & & Normal ICP & \\
\hline LBW & 26 & 20.8 & 14 & 11.2 \\
\hline Preterm & 22 & 17.6 & 12 & 9.6 \\
\hline Large baby & 3 & 2.4 & 7 & 5.6 \\
\hline Anomalous baby & 3 & 2.4 & - & - \\
\hline
\end{tabular}

Table 5: Reasons of NICU admissions.

\begin{tabular}{|lllll|}
\hline \multirow{2}{*}{ Reason of NICU admission } & No. of cases & Percentage & No. of cases & Percentage \\
\cline { 2 - 4 } & Short ICP & & Normal ICP & \\
\hline Respiratory distress & 5 & 25 & 4 & 28.5 \\
\hline Hyperbilirubinemia & 3 & 15 & 3 & 21.4 \\
\hline Low birth weight & 6 & 30 & 2 & 14.2 \\
\hline PROM & 3 & 15 & 2 & 14.2 \\
\hline Big baby & 2 & 10 & 2 & - \\
\hline Anomalous baby & 1 & 5 & - & - \\
\hline
\end{tabular}

Table 6: Duration of NICU admissions.

\begin{tabular}{|lllll|} 
& No. of cases & Percentage & No. of cases & Percentage \\
\hline & Short ICP & & Normal ICP & \\
\hline $0-3$ days & 2 & 10 & 1 & 7.1 \\
\hline 3-7 days & 8 & 40 & 7 & 50 \\
\hline 7-14 days & 5 & 25 & 4 & 28.5 \\
\hline$>$ 14 days & 5 & 25 & 2 & 14.3 \\
\hline
\end{tabular}

As shown in Table 5, among the NICU admissions, low birth weight $(30 \%)$ was the commonest indication for admission among those with short interpregnancy interval whereas respiratory distress $(28.5 \%)$ was the most common indication for admission among those with normal interpregnancy interval. Low birth weight babies had the maximum duration of stay in NICU and those with PROM and large for gestational babies had the minimum duration.

As shown in Table 6, majority of the cases had NICU stay of 3-7 days (40\% of short ICP cases and $50 \%$ of long ICP cases. Least number of cases were seen in 0-3 days.

\section{DISCUSSION}

Most of the study subjects were aged between 25-30 years. As per NCHS data, the percentage of births to mothers with intervals of 12-17 months increased with increasing maternal age at previous birth: from $8.4 \%$ among mothers under age 20 to $22.1 \%$ among mothers aged over 35.4 All the characteristics and complications of women with short and normal interpregnancy interval were compared, however only the significant ones have been highlighted.

The estimated incidence of anemia among pregnant women in India is 50\% (National Family Health Survey 2015-2016). In our study, as shown in Figure 1, incidence of anemia was found to be $66 \%$ in women with short interpregnancy interval which is significantly higher than the national average and $52 \%$ in women with normal interpregnancy interval. (The results of this study cannot be applied to the general population as our tertiary health centre caters to a large number of referred cases).

Few studies have found that women with shorter interpregnancy interval have higher risk of maternal mortality, hypertensive disorders of pregnancy, bleeding and anemia. Studies conducted in developing countries suggest longer interpregnancy interval- 3 to 5 years as the optimal interpregnancy interval. ${ }^{5}$

The incidence of uterine scar dehiscence ranges between 0.2 and $4.3 \%$ of all pregnancies with previous caesarean. 6 In our study scar dehiscence was found in up to $16 \%$ patients with previous cesarean with short 
interpregnancy interval. In similar studies, scar dehiscence was reported in $65 \%$ of patients with interpregnancy interval less than 18 months and in only $6.66 \%$ of patients with interpregnancy interval more than 24 months. $^{7}$ A longer time interval after a previous cesarean section gives more quality attributes to the scar. ${ }^{8}$ Scar dehiscence is found in up to $6 \%$ women with normal interpregnancy interval in this study.

Incidence of preterm labour was found to be $5.8 \%$ and between $7-9 \%$ in various studies. ${ }^{9,10}$ In our study $17.6 \%$ patients went into preterm labour, establishing short interpregnancy interval as a risk factor for preterm labour. In contrast only $9.6 \%$ patients with normal interpregnancy interval went into preterm labour. The prevalence of low birth weight in developing countries $(16.5 \%)$ is twice than in developed regions $(7 \%) .{ }^{11}$ In this study $20.8 \%$ patients with short interpregnancy interval delivered low birth weight baby whereas $11 \%$ patients with normal interpregnancy had low birth weight babies as shown in Table 6.

Hypertensive disorders of pregnancy are associated with both short (< 12 months) and long ( $>72$ months) interpregnancy intervals. ${ }^{12}$ Hypertensive disorders of pregnancy may complicate $3-10 \%$ of all pregnancies with variable incidence among different hospitals and countries. ${ }^{13}$ In this study the incidence was $6.8 \%$ in women with short interpregnancy interval and $19.2 \%$ in women with normal interpregnancy interval.

Short interpregnancy interval is associated with greater incidence of anemia, preterm labour, scar dehiscence and low birth weight babies. On the other hand, hypertensive disorders are seen more commonly in women with normal interpregnancy interval.

\section{ACKNOWLEDGMENTS}

Authors would like to thank Dr. Ashok Anand Sir, Professor and Head of department, obstetrics and gynaecology and all the pregnant women who gave consent to participate in this study.

Funding: No funding sources Conflict of interest: None declared

Ethical approval: The study was approved by the Institutional Ethics Committee

\section{REFERENCES}

1. Eleje GU, Ezebiala IU, Eke NO. Interpregnancy Interval (IPI): What is the ideal? Afrimedic J. 2011;2(1):6-38.
2. Post M. HTSP 101: Everything you want to know about healthy timing and spacing of pregnancy; 2007.

3. DaVanzo J, Hale L, Razzaque A, Rahman M. The effects of birth spacing on pregnancy outcomes and infant and child mortality in Matlab Bangladesh. [Unpublished] 2004. Presented at the annual meeting of the Population Association of America Boston Massachusetts; 2004.

4. Da Vanzo J, Hale L, Razzaque A, Rahman M. The effects of pregnancy spacing on infant and child mortality in Matlab, Bangladesh: How they vary by the type of pregnancy outcome that began the interval. Popul Stud (Camb) 2008;62:131-54.

5. Thoma ME, Copen CE, Kirmeyer S. Short interpregnancy intervals in 2014: differences by maternal demographic characteristics. US Department of Health and Human Services, Centers for Disease Control and Prevention, National Center for Health Statistics; 2016.

6. Zilberman B. Influence of short interpregnancy interval on pregnancy outcomes. Harefuah. 2007;146(1):42-7.

7. Baron J, Weintraub AY, Eshkoli T, Hershkovitz R, Sheiner E. The consequences of previous uterine scar dehiscence and cesarean delivery on subsequent births. Int J Gynaecol Obstet. 2014;126(2):120-2.

8. Tyagi N, Prabhakar M, Tyagi S. Retrospective study to find predictive factors of scar dehiscence in previous cesarean section to prevent maternal and perinatal morbidity and mortality. Int J Reprod Contracept Obstet Gynecol. 2019;8(2);531-5.

9. Basic E, Basic-Cetkovic V, Kozaric H, Rama A. Ultrasound evaluation of uterine scar after cesarean section. Acta Informat Medica. 2012;20(3):149-53.

10. Rao CR, Ruiter LE, Bhat P, Kamath V, Kamath A, Bhat V. A case control study on risk factors for preterm deliveries in a Secondary care hospital, southern India." Obstet Gynaecol. 2014:Article ID 935982.

11. Jamal $\mathrm{S}$ et al. A retrospective analytical study of the epidemiology and causes of preterm birth. Int J Reprod Contracept Obstet Gynecol. 2017;6(12):5453-7.

12. Bharati P, Pal M, Bandyopadhyay M, Bhakta A, Chakraborty S, Bharati P. Prevalence and causes of low birth weight in India. Malaysian $\mathrm{J}$ Nutrit. 2011;17(3):45-56.

13. Mignini LE, Carroli G, Betran AP, Fescina R, Cuesta C, Campodonico $\mathrm{L}$, et al. Interpregnancy interval and perinatal outcomes across Latin America from 1990 to 2009: a large multi-country study. BJOG. 2016;123:730-7.

14. Barron WM, Murphy MB, Lindheimer MD. In: Management of hypertension during pregnancy. 3rd ed. Raven. Laragh GH, Brenner BM, editors. Vol 2. New York: Hypertension pathophysiology, diagnosis and management; 1990;163(2):1691-1712.

Cite this article as: Lewis P, Mor S. Study on fetomaternal outcome in short interpregnancy interval: case control study. Int J Reprod Contracept Obstet Gynecol 2020;9:583-7. 